\title{
Design and Analysis of In-Wheel Double Stator Slotted Rotor BLDC Motor for Electric Bicycle Application
}

\author{
S. Farina ${ }^{1}$, R.N. Firdaus ${ }^{2}$, F. Azhar ${ }^{3}$, M. Azri ${ }^{4}$, M. S. Ahmad ${ }^{5}$, R. Suhairi ${ }^{6}$, \\ A. Jidin ${ }^{7}$, T. Sutikno ${ }^{8}$ \\ 1,2,3,4,5,6,7 Faculty of Electrical Engineering, Universiti Teknikal Malaysia Melaka, Malaysia \\ 1,2,3,4,5,6,7 Electrical Machine Design, Power Electronics and Drives Research Group, CeRIA, UTeM. \\ ${ }^{6}$ Electrical Technology Section, Universiti Kuala Lumpur-British Malaysian Institute, Malaysia. \\ ${ }^{8}$ Universitas Ahmad Dahlan, Indonesia.
}

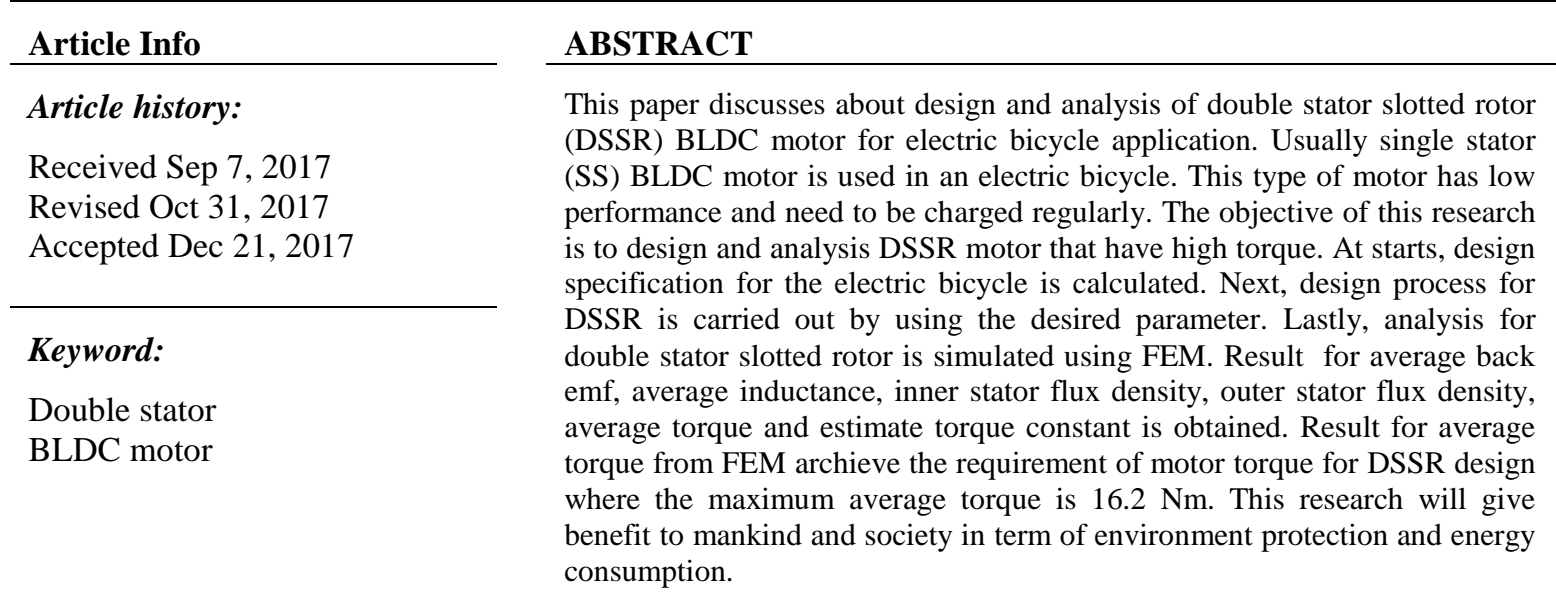

Copyright $@ 2018$ Institute of Advanced Engineering and Science. All rights reserved.

\section{Corresponding Author:}

R.N. Firdaus,

Faculty of Electrical Engineering, Universiti Teknikal Malaysia, Melaka, Malaysia

Hang Tuah Jaya, 76100 Durian Tunggal, Melaka, Malaysia.

Email: norfirdaus@utem.edu.my

\section{INTRODUCTION}

Recently, the accelerated development in the number of vehicle in use has seriously impacted on worldwide energy consumption and environment. Compared to the internal combustion engine vehicles, electric vehicles contribute significantly to the energy saving and environmental protection, and on account of these benefits, they constitute today's direction for the automotive industry [1]. With growing concerns on environment protection and energy conservation, electric vehicles have gained increasing attention [1-3]. Different from the internal combustion vehicles, electric vehicle have an electric motor embedded in the powertrain. Since the efficiency in the energy conversion of an electric motor together with the associated power electronics supply is much higher than internal combustion vehicles, electric vehicle need less energy to move [4]. Furthermore, exploiting the capabilities of the electric motors, additional abatement in energy consumption can be achieved.

For instance, the start-stop and the regenerative braking features can further reduce the energy consumption by approximately 20\%-30\% [4]. Therefore, electric vehicle are convenient, not only for increasing the efficiency in the energy utilization, but also for cutting out environmental pollution in an equal proportion [4]. There are many type of electric vehicle which include electric scooter, electric skateboard, hoverboard, and electric moped scooter. Electric bicycle is one of the electric vehicle which uses electric motor for propulsion. There are a great variety of electric bicycle available worldwide from electric bicycle 
that have a small motor to assist the rider pedal power to more powerful electic bicycle which tend closer to style functionality and performance. Electric bicycle uses rechargeable batteries and can travel up to $25 \mathrm{~km} / \mathrm{h}$. Single stator (SS) BLDC motor is often used for electric bicyle. The problem with SS motor is that it produce low power and low torque. When using SS motor, the electric bicycle will have low performance and need to be charge regularly. To overcome this problem, double stator slotted rotor motor (DSSR) is introduce. DSSR have high torque torque and high power. Due to the special structure of double stator, where it has two stator that will double all the parameter, DSSR higher performance compared to SS which could increase the usage time.

Double stator motor is widely used in electric vehicle because of its high power and high efficiency [4-11]. Some author uses double stator for hybrid electric vehicle (HEV) [12]. Compared with conventional permanent magnet electric machines, double stator has the advantage that currents of both the inner and outer stators produce electromagnetic torque and two air-gaps can deliver the output torque, thus improving the torque density and providing a high starting torque for cold cranking. Because of the nature of double stator windings, the machine can flexibly change their connections, hence providing a constant output voltage over a wide speed range for battery charging [12-14]. Another author present paper about design of the double stator permanent magnet synchronous starter and generator used in electric vehicles permanent magnet double stator intergrated starter generator for hybrid electric vehicle (HEV).

The double stator permanent magnet synchronous starter generator was designed to have different number slots in inner stator and in the outer stator and poles at double attached magnet rotor is also different. Two machines consist of the outer stator, the inner stator and double attached magnet rotor two machines with different combinations of poles and slots to can be designed separately to achieve optimum performance and to meet the demand of different operation modes [15]. Another researcher studied performance analysis of double-stator starter for the hybrid electric vehicle. When double stator works as a motor at low speeds, the two armature windings are in series, so the output torque of the motor is large. When it works as a machine, the composite voltage vector of the two stators windings can be altered through shifting the relative position of the two stators. All of the above characteristics meet the demands of the motor used in the HEV very well [16].

\section{DESIGN SPECIFICATION}

The electric bicycle performance need to be estimated in term of total force needed by the bicycle when moving towards the road. Equation (1) shows the total force where $f_{\mathrm{g}}$ is the hill climbing force, while $f_{\text {air }}$ and $f_{\mathrm{r}}$ is the force when bicycle is moving through air and rolling force respectively. Figure 1 shows the diagram of force characteristic in typical bicycle and all the force needed by the bicycle in order to move forward.

$$
f_{\text {total }}=f_{g}+f_{\text {air }}+f_{r}
$$

The hill climbing force, $f_{\mathrm{g}}$ is given in equation (2) where $m$ is the mass of the bicycle, $g$ is the gravitational force and $\theta$ is the road gradient;

$$
f_{g}=(m)(g)(\sin \theta)
$$

The second force is $f_{\text {air }}$ where this force appears when bicycle moves forwards and moving through air, where $c d$ is drag coefficient, $\rho$ is air density, $A$ is moving area, $v_{\mathrm{r}}$ is relative speed in air. Equation (3) define about this force.

$$
\begin{gathered}
f_{a i r}=(c d)(\rho)(A)\left(\frac{v_{r}^{2}}{2}\right) \\
v_{r}=v_{a}+v_{b}
\end{gathered}
$$

Relative speed in air is equal to air speed and ground speed which is shown in equation (4) where $v_{\mathrm{a}}$ is air speed while $v_{\mathrm{b}}$ is ground speed. 


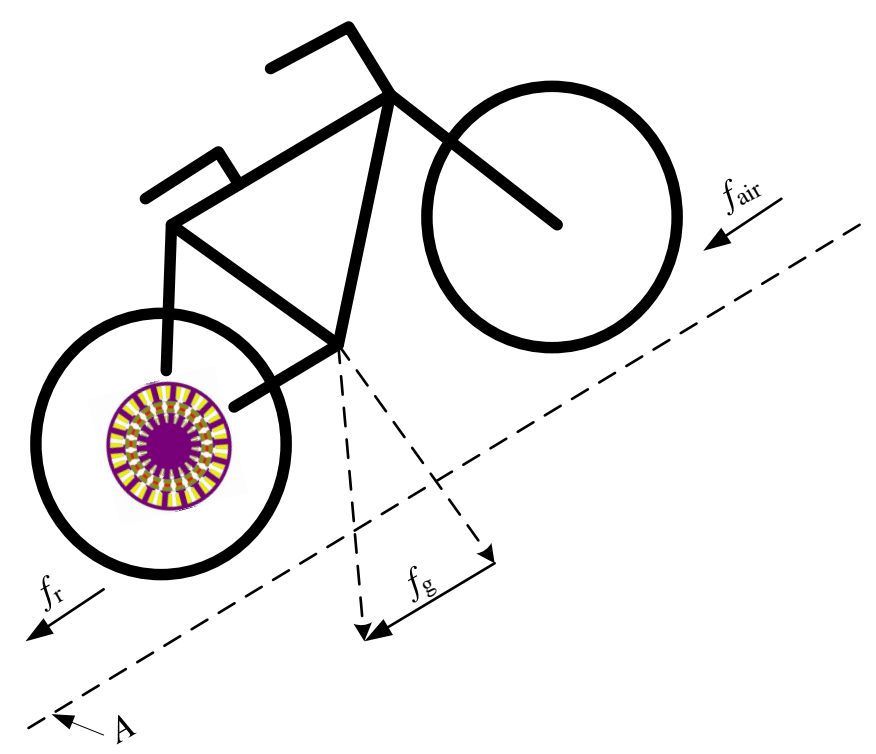

Figure 1. Diagram of force characteristic in typical bicycle

The last force is $f_{\mathrm{r}}$ which is the rolling force. This rolling force is cause by the bicycle weight including the rider and tire friction on the road. Equation (5) shows the rolling force while equation (6) shows the rolling coefficient where it depends on tire pressure and tire type where, $W$ is weight in pound while $X$ and $Y$ is the tire pressure values;

$$
\begin{aligned}
& f_{r}=\left(C_{r r}\right)(m g) \\
& C_{r r}=X+\frac{Y}{W}
\end{aligned}
$$

By using equation (2), (3), (4), (5) and (6) the specific condition parameter is obtained. The condition is based on basic collected data by the researcher. Parameter for typical bicycle is shown in Table 1 . From the table, mass of bicycle and weight of rider is $40 \mathrm{~kg}$ and $70 \mathrm{~kg}$ respectively. The road radient is $5 \%$ while air speed is assume $0 \mathrm{~ms} / \mathrm{s}$. The speed change form $0 \mathrm{~km} / \mathrm{h}$ to $25 \mathrm{~km} / \mathrm{h}$. Tire radius of the bicyle is 0.365 . The drag coefficient, frontal area and air density is $1,0.4 \mathrm{~m}^{2}$ and $1.197 \mathrm{~kg} / \mathrm{m}^{3}$ respectively.

Table 1. Data of typical bicycle

\begin{tabular}{llc}
\hline Parameter & & Value \\
\hline Mass of bicycle, $m_{\mathrm{b}}$ & $\mathrm{Kg}$ & 40 \\
Weight of rider, $w_{\mathrm{r}}$ & $\mathrm{Kg}$ & 70 \\
Road radient, $\theta$ & $\%$ & 5 \\
Air speed, $V_{\mathrm{a}}$ & $\mathrm{m} / \mathrm{s}$ & 0 \\
Speed range, $n$ & $\mathrm{~km} / \mathrm{h}$ & $0-25$ \\
Tire radius, $T_{\mathrm{r}}$ & $\mathrm{m}$ & 0.365 \\
Drag coefficient, $C_{\mathrm{d}}$ & & 1 \\
Frontal area, $A$ & $\mathrm{~m}^{2}$ & 0.4 \\
Air density, $p$ & $\mathrm{Kg} / \mathrm{m}^{3}$ & 1.197 \\
\hline
\end{tabular}

To obtained torque, equation (7) is used. For the calculation of motor torque and human torque, equation (8) and (9) is applied, respectively. Where $f_{\text {total }}$ is obtained from equation (1), $T_{\mathrm{r}}$ is tire radius, and $R$ is ratio of motor torque over human torque.

$$
\begin{aligned}
& T=f_{\text {total }} \times T_{r} \\
& T_{\text {motor }}=T \times R
\end{aligned}
$$




$$
T_{\text {human }}=T-T_{\text {motor }}
$$

Figure 2 shows torque requirement for the bicycle in this research. Figure 2 (a) is the torque requirement where total motor torque is the torque produce by load which is proportional to force and distance of the bicyle. Maximum torque for motor at speed $20 \mathrm{~km} / \mathrm{h}$ is $10 \mathrm{Nm}$ while minimum torque produce is $8 \mathrm{Nm}$. Total human torque is the torque contribute by human which is produce by rotating bicyle pedal manually. Maximum torque produce by human force is $16 \mathrm{Nm}$ while minimum torque is $14.5 \mathrm{Nm}$. Total torque is the result after adding up both motor torque and human torque. Total maximum and minimum torque produce by both force is $26 \mathrm{Nm}$ and $22.5 \mathrm{Nm}$, respectively. The different between torque produce by motor and human is $50 \%$. As torque of the motor increase, human torque will be increased. Maximum ratio for motor torque over human torque is 0.5. Figure 2 (b) shows output power estimation. The power is estimated for torque produce by motor only. At speed $200 \mathrm{rpm}$, the power estimated is $19 \mathrm{~W}$ while torque produce by motor is $10 \mathrm{Nm}$. Motor speed at this point is $23.9 \mathrm{~km} / \mathrm{h}$ when being converted from revolutions per minute $[\mathrm{rpm}]$. From the figure, it can be seen that output power increase as speed of the motor increase and speed in kilometres per hour $(\mathrm{km} / \mathrm{h})$ is perpendicular with speed in $\mathrm{rpm}$.

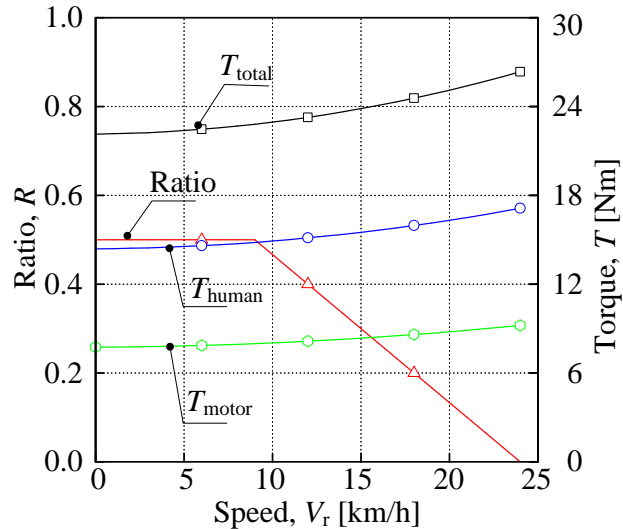

(a) Torque requirement

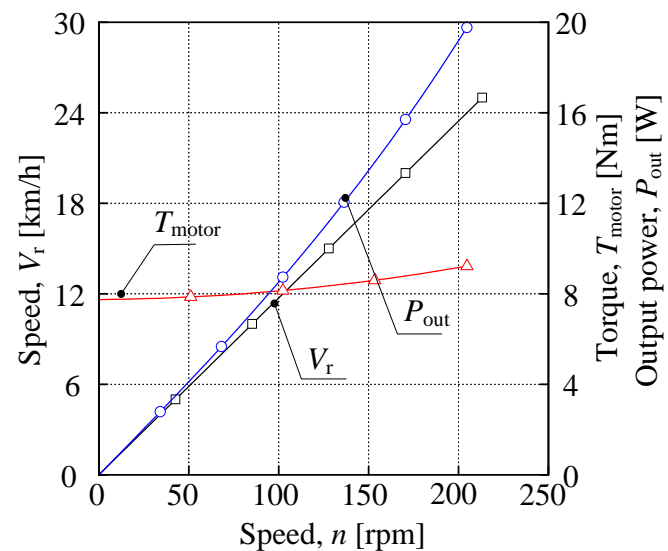

(b) Output power estimation

Figure 2. Requirement for the bicycle in this research

\section{DESIGN OF DSSR}

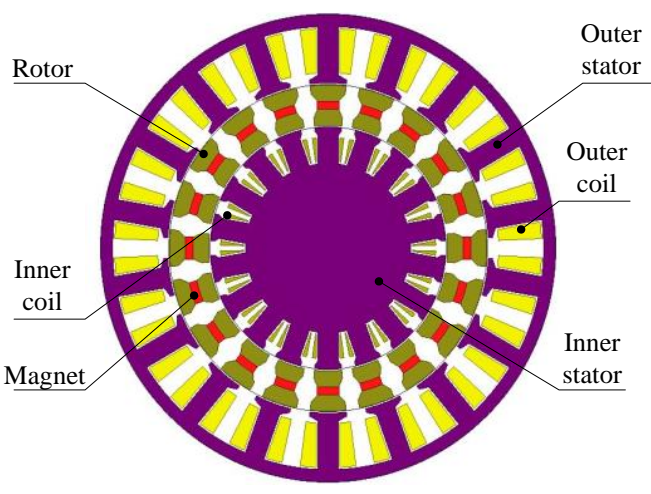

a) Basic structure

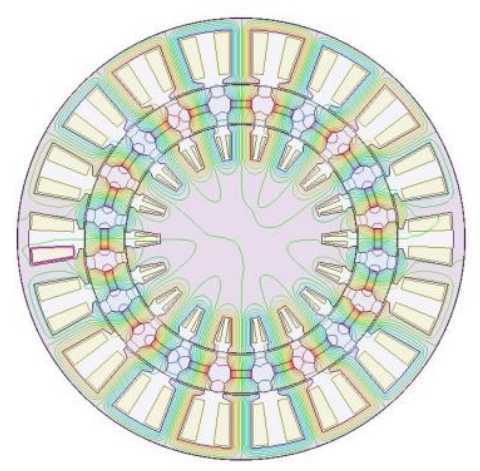

b) Flux line 


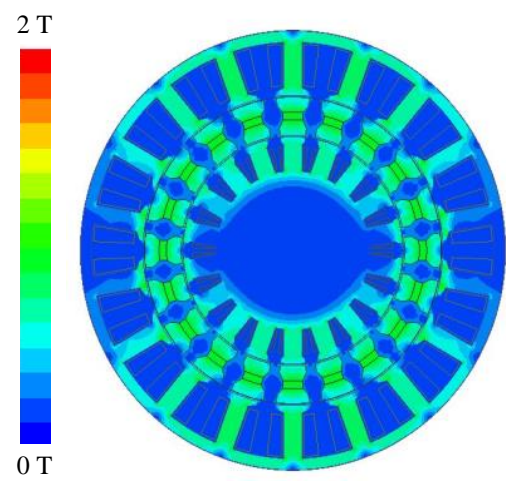

c) Magnetic flux density

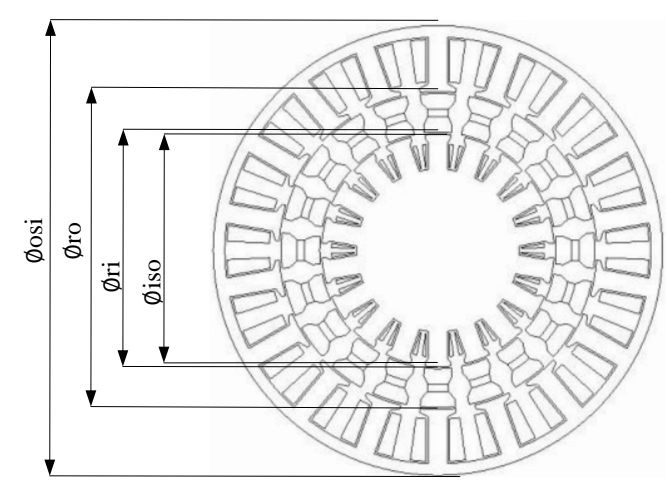

d) Parameter configuration

Figure 3. Double stator configuration

Figure 3 shows overall double stator configuration which consist of basic structure, flux line, magnetic flux density and parameter configuration. Figure 3 (a) is the basic structure of DSSR. In a DSSR, there is two stator, which is inner stator and outer stator, coil winding at each stator, permanent magnet and rotor. Figure 3 (b) is the flux of DSSR. The flux line moves from permanent magnet towards stator back to permanent magnet, completing a circle from north to south. Figure 3 (c) is magnetic flux density of DSSR. Further explanation of magnetic flux density is explained in Figure 4 (c) and 4 (d). Figure 4 (d) shows the double rotor configuration.

The detail value for each configuration is explain in Table 2. Table 2 is design parameter of DSSR BLDC. Based on the table, the Outer stator diameter, $\emptyset_{\text {osi }}$ is $116 \mathrm{~mm}$ while the inner stator outer diameter, $\emptyset$ iso is $82 \mathrm{~mm}$. The rotor outer diameter, Øiro and Rotor inner diameter, Øri is $81 \mathrm{~mm}$ and $61 \mathrm{~mm}$, respectively. The mechanical air gap for both inner and outer is $0.5 \mathrm{~mm}$. Both mechanical air gap have the same value so that flux will flow equally in both air gap. This motor is design for three phase configuration with number of turn for outer stator is 100 and 58 for inner stator. The number of slot and pole for this double rotor is 18 and 20 respectively. Permanent magnet volume is $3.78 \times 10^{3}$ while permanent magnet size is 5.4 $\mathrm{mm} \times 2 \mathrm{~mm} \times 35 \mathrm{~mm}$. The coil diameter for winding purpose is $1.0 \mathrm{~mm}$. Stack length for the double stator motor is $35 \mathrm{~mm}$.

Table 2: Design parameter of DSSR BLDC

\begin{tabular}{|c|c|c|c|}
\hline Item & & Element & Value \\
\hline Outer stator & {$[\mathrm{mm}]$} & Outer stator diameter & 116 \\
\hline \multirow{2}{*}{ Number of turn } & & Outer stator & 100 \\
\hline & & Inner stator & 58 \\
\hline Inner stator outer diameter, $\emptyset$ iso & {$[\mathrm{mm}]$} & 82 & \\
\hline Rotor outer diameter, Øro & {$[\mathrm{mm}]$} & 81 & \\
\hline Rotor inner diameter, $\emptyset$ ri & {$[\mathrm{mm}]$} & 61 & \\
\hline Number of slots & & 18 & \\
\hline Number of poles & & 20 & \\
\hline Number of phase & & 3 & \\
\hline Permanent magnet volume & {$[\mathrm{mm}]$} & $3.78 \times 10^{3}$ & \\
\hline Permanent magnet size & {$[\mathrm{mm}]$} & $5.4 \times 2 \times 35$ & \\
\hline Coil size & {$[\mathrm{mm}]$} & 1.0 & \\
\hline Stack length & {$[\mathrm{mm}]$} & 35 & \\
\hline Outer air gap & {$[\mathrm{mm}]$} & 0.5 & \\
\hline Inner air gap & {$[\mathrm{mm}]$} & 0.5 & \\
\hline
\end{tabular}

\section{ANALYSIS OF DSSR FOR ELECTRIC BICYCLE APPLICATION}

Figure 5 shows FEM analysis result of double stator slotted rotor BLDC motor for electric bicycle application. Condition of each parameter is explained at each graph. Figure 5 (a) is average backemf. Backemf during zero current where the changes of backemf, $E$ is shown interm of changes magnetic flux, $\phi$ towards time, $t$ as shown in equation (9). The equation of backemf is according to Faraday,s law where $\phi$ is the magnetic flux of the motor and $t$ is the changes in time. 


$$
E=-\frac{d \phi}{d t}
$$

Based on Figure 5 (a), the minimum backemf is $20 \mathrm{~V}$ while maximum backemf is $100 \mathrm{~V}$. Backemf increase propotionally to the increase of speed. Speed of back emf is varied from $200 \mathrm{rpm}$ to $1000 \mathrm{rpm}$. As motor rotate at higher speed, more magnetic flux is created which influenced the increment of backemf.

Figure 5 (b) is result for average inductance which is from FEM analysis. Current at this point is varied from 2 A to 10 A while speed is at the range of $200 \mathrm{rpm}$ to $1000 \mathrm{rpm}$. Relationship between back emf, inductance and current is shown in equation (10) where the induced voltage back emf, $E$ is equal to motor inductor's inductance, $L$ and the rate of change of current, $i$ through the inductor. Maximum inductance is $0.035 \mathrm{H}$ for current of $2 \mathrm{~A}$ while minimum inductance, is $0.025 \mathrm{H}$ for current of $10 \mathrm{~A}$. Inductance increase linearly with the increase of current but there is no significant difference of inductance value when speed is increase at all current level. From current $2 \mathrm{~A}$ to $4 \mathrm{~A}$ there is only some significant change of inductance. This is the same for current $8 \mathrm{~A}$ to $10 \mathrm{~A}$.

$$
E=L \frac{d i}{d t}[\mathrm{~V}]
$$

Figure 5 (c) and 5 (d) shows result for inner stator flux density and outer stator flux density, respectively when current is varied from 2 A to 10 A and speed is in the range of $200 \mathrm{rpm}$ to $1000 \mathrm{rpm}$. Maximum inner stator flux density is $1.9 \mathrm{~T}$ while minimum inner stator flux density is $1.1 \mathrm{~T}$. For outer stator flux density, maximum flux density is $2.0 \mathrm{~T}$ at current $10 \mathrm{~A}$ while minimum flux density is $1.3 \mathrm{~T}$ at $2 \mathrm{~A}$. The similarity between inner stator flux density and outer stator flux density is that the flux density increase when current is increase. Both flux density in occur in range of $1.0 \mathrm{~T}$ to $2.0 \mathrm{~T}$. The difference between both flux density in term of maximum and minimum value is $5 \%$ and $12 \%$, respectively. The best flux density appear at current $6 \mathrm{~A}$. When current is change to $8 \mathrm{~A}$ and $10 \mathrm{~A}$, motor start to saturate.

Figure 5 (e) shows average torque result. The result is obtained during current 2 A to $10 \mathrm{~A}$ while speed is in the range of $200 \mathrm{rpm}$ to $1000 \mathrm{rpm}$. The maximum average torque is $16.2 \mathrm{Nm}$ while minimum average torque is $4.2 \mathrm{Nm}$. This is in the range of motor torque which had beed discussed in Figure 2. Torque increased when current is increased but maintain for different speed. There is only small increment of torque from current $8 \mathrm{~A}$ to $10 \mathrm{~A}$. This shows that the best operating current of the motor is at $6 \mathrm{~A}$. The relationship between torque with current is shown in equation (11) where $P$ is number of pole, $Z$ is number of conductor, $\phi$ is flux per pole, $I$ is armature current and $A$ is number of parallel path.

$$
T=\frac{P Z \phi I}{2 \pi A}[\mathrm{Nm}]
$$

Figure 5 (f) shows torque vs speed result. This result is obtained by using equation (12) and (13). Stall torque of the motor is $600 \mathrm{Nm}$ where the output rotational speed is zero. Stall torque is the maximum torque can be applied to the shaft and cause the motor to stop rotating. The maximum output speed of the motor is $140 \mathrm{rpm}$. This is the motor condition when no torque is applied to the shaft. Operating requirement for the motor is shown in the graph where motor operates at the range point. Torque and speed characteristic is at $48 \mathrm{~V}$.

The relationship between torque constant, current and speed is shown in equation (12) and (13) Where $V$ is the voltage source, $k_{\mathrm{t}}$ is constant current, $k_{\mathrm{e}}$ is contant voltage, $R_{\mathrm{c}}$ is coil resistance, and $\omega$ is speed during no load condition. From the equation, it can be seen that torque increased linearly with the increased of $k_{\mathrm{t}}$ and $k_{\mathrm{e}}$ but speed during no load decreased with the increased of $k_{\mathrm{e}}$.

$$
\begin{aligned}
T_{c}=\frac{V k_{t}^{2} k_{e}}{R_{c}} & {[\mathrm{Nm}] } \\
\omega & =\frac{V}{k_{e}}[\mathrm{rpm}]
\end{aligned}
$$




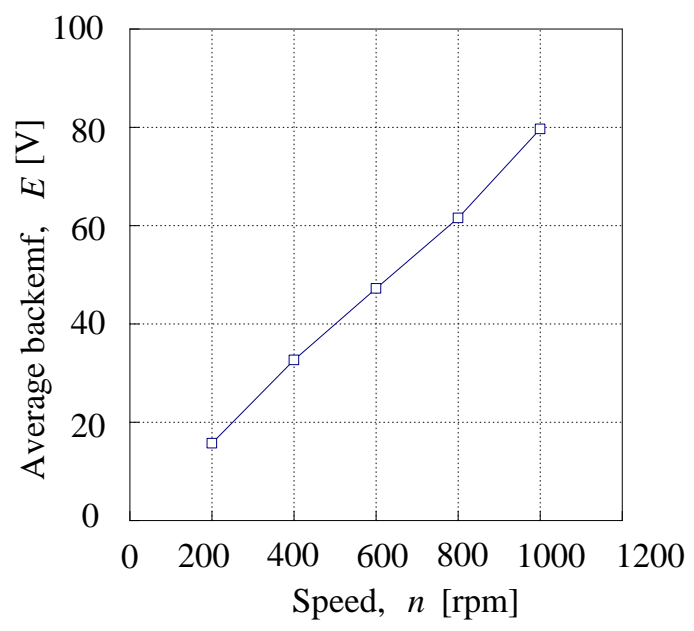

a) Average backemf

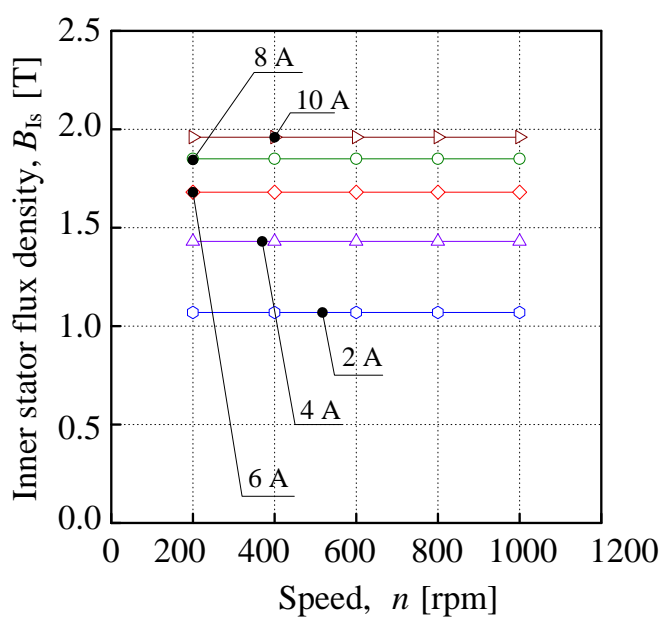

c) Inner stator flux density

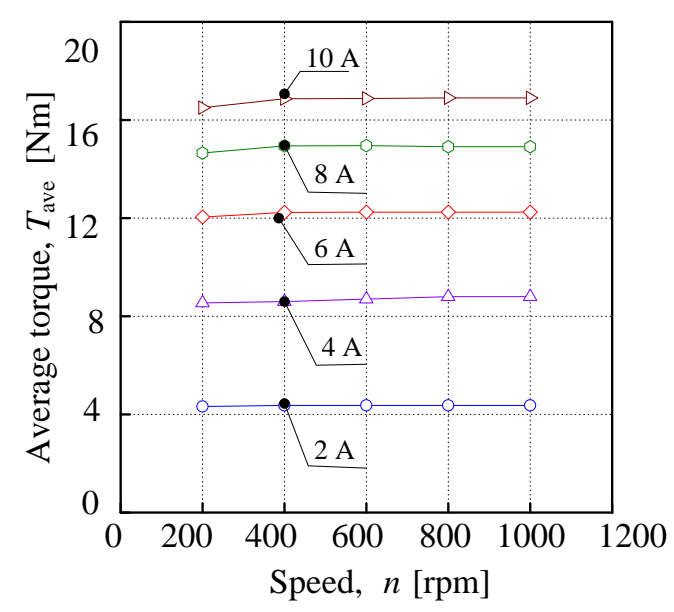

e) Average torque

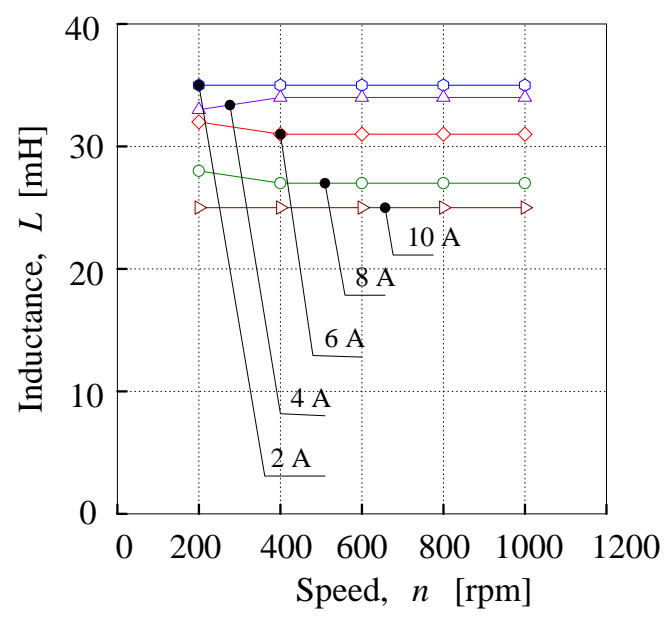

b) Average inductance

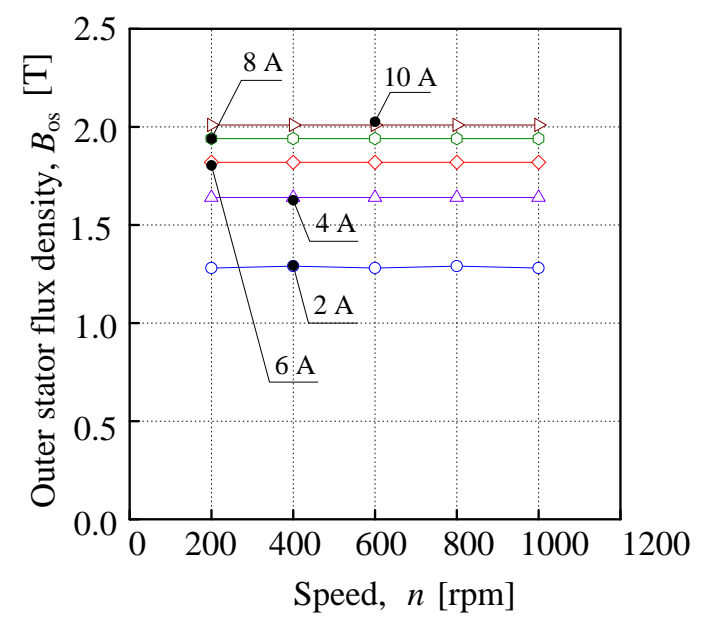

d) Outer stator flux density

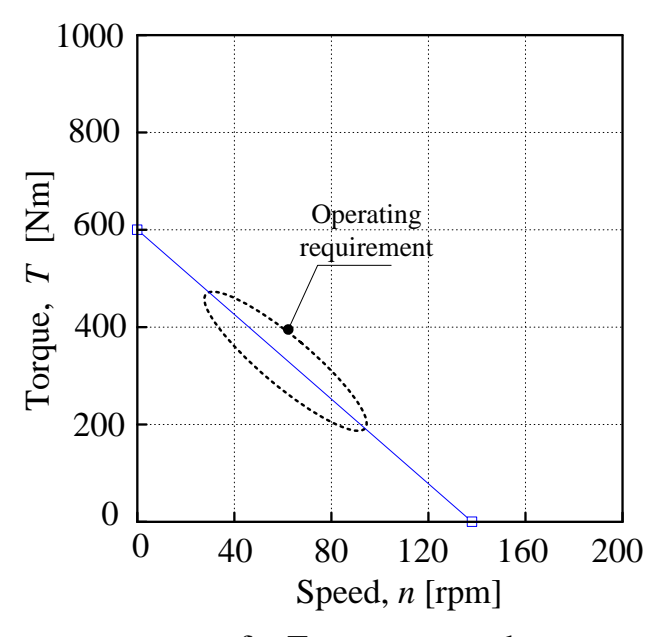

f) Torque vs speed

Figure 4. FEM analysis

\section{CONCLUSION}

In this paper, design and analysis of double stator slotted rotor BLDC for electric bicycle had been discussed. Firstly, electric bicycle performance need to be estimated in term of total force needed by the 
bicycle when moving towards the road. As a result expected, torque and power is estimated and double stator was designed in term of basic structure, flux line, magnetic flux density and parameter configuration. Lastly, analysis for double stator slotted rotor using FEM analysis and result for average back emf, average inductance, inner stator flux density, outer stator flux density, average torque and estimate torque vs speed is obtained. Result for average torque from FEM result archieve the requirement of motor torque for DSSR where the maximum average torque is $16.2 \mathrm{Nm}$..

\section{ACKNOWLEDGEMENTS}

The author would like to thank Skim Zamalah UTeM for supporting this research in order to ensured the project be successful.

\section{REFERENCES}

[1] N. Shuangxia, K.T. Chau, J.Z. Jiang, "A Permanent-magnet Double-stator Integratedstarter-generator for Hybrid Electric Vehicles," IEEE Vehicle Power and Propulsion Conference (VPPC), September 3-5, 2008, Harbin, China, $1-6$, Sept 2008.

[2] P. Yulong, C. Feng, S. Jia, C. Shukang, "Design of the Double-stator Permanent Magnet Synchronous Starter and Generator Used in Electric Vehicles," International Conference on Electrical Machine and Systems (ICEMS), 1-4, Nov 2011.

[3] F. Chai, S. Cui, and S. Cheng, "Performance Analysis of Double-Stator Starter Generator for the Hybrid Electric Vehicle," IEEE Transaction on Magnetics, Vol. 41. no. 1, 484-487, Jan 2005.

[4] C. Ming, S. Le, B. Giuseppe, and S. Lihua, "Advanced Electrical Machines and Machine-Based Systems for Electric and Hybrid Vehicles," Energies 2015, Vol. 8. 9541-9564, Sept 2015.

[5] M. J. Hoeijmakers and J. A. Ferreira, "The electric variable transmission,"IEEE Transaction on Industrial Application, Vol. 42. no. 4, 1092-1100, Jul. 2006.

[6] Y. Cheng, S. M. Cui, and C. C. Chan, "The study of the operation modes and control strategies of an advanced electromechanical converter for automobiles," IEEE Transaction on Magnetics, Vol. 43, no. 1, 430-433, Jan. 2007.

[7] K. T. Chau, C. C. Chan, and C. Liu, "Overview of permanent-magnet brushless drives for electric and hybrid electric vehicles," IEEE Transactions on Industrial Electronics, Vol. 55. no. 6, 2246-2257, Jun. 2008.

[8] H. C. Lovatt, V. S. Ramsden, B. C. Mecrow, "Design of an in-wheel motor a solar-powered electric vehicle," IEEE proceedings Electrical Power Applied, Vol. 145, no. 5, 402-408, Sept 1998.

[9] A.Balakrishnan., Electrical Machines-1. Engineering series, Perpustakaan Negara Malaysia, 2008.

[10] R. Suhairi, R. N. Firdaus, M. N. Othman, M. Z. N. Aishah, F.Azhar, M. I. S. Zulaika, Z. Ibrahim and A. Vaithilingam, "Modeling and Analysis of Double Stator Slotted Rotor Permanent Magnet Generator" Energies 2017, Vol. 10. 1-15, March 2017

[11] R. Suhairi1, R. N. Firdaus1, M. Z. Aishah1, F. Azhar1, M. N. Othman, , Z. Ibrahim1, and C. V. Aravind, "Performance Characteristics of Non-Arc Double Stator Permanent Magnet Generator," Progress In Electromagnetics Research M, Vol. 5, 201-214, 2017

[12] W. H. Tai, M. C. Tsai, Z. L. Gaing, P. W. Huang, and Y. S. Hsu, "Novel Stator Design of Double Salient Permanent Magnet Motor" IEEE Transaction on Magnetics, Vol. 50, no. 4, 1-4, April 2014

[13] C. Feng, C. Shumei, and C. Shukang, "Study of A Novel Double-stator Permanent-magnet Electric Machine" IEEE International Conference on Electric Machines and Drives Conference, 2003. IEMDC'03, 1375-1378, June 2003.

[14] A. Muntean, M.M. Radulescu and A. Miraoui, "Torque analysis and control of a double-layer interior permanentmagnet synchronous motor for electric vehicle propulsion applications" 8th International Symposium on Advanced Electromechanical Motion Systems \& Electric Drives Joint Symposium, 2009. ELECTROMOTION 2009, 1-8, July 2009

[15] Y. Wang, M. Cheng, Y. Fan and K.T. Chau, "A Double-Stator Permanent Magnet Brushless Machine System for Electric Variable Transmission in Hybrid Electric Vehicles" IEEE Conference on Vehicle Power and Propulsion (VPPC), 2010, 1-5, Sept 2010

[16] E. Odv, A. Mebarki, D. Gerada, N. Brown, "Electric Motor-Generator for a Hybrid Electric Vehicle," Engineering MECHANICS, Vol. 16, no. 2, 131-139, 2009 